27 Taylor K, Thompson S, Davis R. Delivering culturally appropriate residential rehabilitation for urban Indigenous Australians: a review of the challenges and opportunities. Aust NZ J Publ Health 2010; 34 (s1): S36-40.

28 Vederhus JK, Kristensen $\varnothing$, Laudet A, Clausen T. Attitudes towards 12step groups and referral practices in a 12-step naive treatment culture; a survey of addiction professionals in Norway. BMC Health Serv Res 2009; 9: 147

29 Huriwai T, Sellman JD, Sullivan P, Potiki TL. Optimal treatment for Maori with alcohol and drug-use-related problems: an investigation of cultural factors in treatment. Subst Use Misuse 2000; 35: 281-300.

30 Whiteford $\mathrm{H}$, Harris M, Diminic S. Mental health service system improvement: translating evidence into policy. Aust NZ J Psychiatry 2013; 47: 703-6.

31 Prussing E. Sobriety and its cultural politics: an ethnographer's perspective on 'culturally appropriate' addiction services in Native North America. Ethos 2008; 36: 354-75.

32 Meier P. A National Survey of Retention in Residential Rehabilitation Services. National Treatment Agency for Substance Misuse, 2005.

33 Marsden J, Farrell M, Bradbury C, Dale-Perera A, Eastwood B, Roxburgh $M$, et al. Development of the treatment outcomes profile. Addiction 2008; 103: 1450-60.

34 Sheerin I, Green T, Sellman D, Adamson S, Deering D. Reduction in crime by drug users on a methadone maintenance therapy programme in New Zealand. NZ Med J 2004; 117: 1-10.
35 Johns K, Baker A, Webster RA, Lewin TJ. Factors associated with retention in a long-term residential rehabilitation programme for women with substance use problems. Ment Health Subst Use Dual Diagn 2009; 2: 40-51

36 Bouchery EE, Harwood HJ, Sacks J Jimon CJ, Brewer RD. Economic costs of excessive alcohol consumption in the US, 2006. Am J Prevent Med 2011; 41: 516-24.

37 Zhang Z, Friedmann PD, Gerstein DR. Does retention matter? Treatment duration and improvement in drug use. Addiction 2003; 98: 673-84

38 Simpson DD, Joe GW, Brown BS. Treatment retention and follow-up outcomes in the Drug Abuse Treatment Outcome Study (DATOS). Psychol Addict Behav 1997; 11: 294

39 Huriwai T, Sellman J, Sullivan P, Potiki T. A clinical sample of Maori being treated for alcohol and drug problems in New Zealand. NZ Med J 1998; 111: 145

40 McNaughton CC. Transitions through homelessness, substance use, and the effect of material marginalization and psychological trauma. Drugs Educ Prev Policy 2008; 15: 177-88.

41 Simpson DD, Joe GW, Broome KM, Hiller ML, Knight K, Rowan-Szal GA Program diversity and treatment retention rates in the Drug Abuse Treatment Outcome Study (DATOS). Psychol Addict Behav 1997; 11: 279.

\title{
New patient assessment in old age psychiatry: the importance of risk assessment
}

\author{
Svetlana Hemsley, ${ }^{1}$ Rebecca McKnight, ${ }_{1}^{1}$ Aneeba Anwar, ${ }^{1}$ Sarah Jones, ${ }^{1}$ Lola Martos ${ }^{1}$
}

BJPsych Bulletin (2015), 39, 227-232, doi: 10.1192/pb.bp.113.046342

${ }^{1}$ South Locality Older Adults Community Mental Health Team, Abingdon

Correspondence to Rebecca McKnight (rebecca.mcknight@ oxfordhealth.nhs.uk

First received 27 Nov 2013, final revision 28 May 2014, accepted 28 July 2014

(C) 2015 The Authors. This is an openaccess article published by the Royal College of Psychiatrists and distributed under the terms of the Creative Commons Attribution License (http:// creativecommons.org/licenses/by/ 4.0), which permits unrestricted use, distribution, and reproduction in any medium, provided the original work is properly cited.

\begin{abstract}
Aims and method In recent years, the role of non-medical community mental health team (CMHT) clinicians has widened to include new patient assessments. It is unclear whether all professionals have the skills and confidence to undertake these to a high quality. This project investigated which professionals are doing new assessments, evaluated their quality and explored the assessors' unmet training needs. The study was based on the data extracted from electronic notes and a complete audit cycle in South Oxfordshire Older Adults CMHT; this was a crosssectional study across Oxfordshire older adults services.
\end{abstract}

Results Most new assessments (72.4\%) were done by non-medical clinicians; the majority were missing important information, especially relating to medications and risk assessment. Only 75\% of assessors felt at least 'partially confident' to do assessments and found them stressful, with $86 \%$ keen to undertake further training.

Clinical implications Simple measures such as an assessment form, a programme of training seminars and adequate supervision, delivered to all CMHT clinicians, can ensure high-quality assessment in diverse clinical environments.

Declaration of interests None.
The discipline of psychiatry has seen many changes in practice over recent years. One major change has been the shifting roles of the multidisciplinary team to include some clinical duties traditionally undertaken by psychiatrists. New patient assessments are one task now frequently delegated to the wider multidisciplinary team. ${ }^{1}$ Non-medical clinicians often have capacity to see the increasing number of referrals arising from an aging population and are a more affordable option than psychiatrists.

Psychiatrists are taught assessment skills gradually throughout their training. Formal teaching in assessment occurs throughout medical school and the foundation 
programme; skills are then enhanced and specialised within psychiatry through weekly supervision, workplace-based assessments and postgraduate examinations. The same structure (focusing on assessment) is not necessarily in place for non-medical professionals. The revised General Medical Council (GMC) Good Medical Practice document provides guidance to doctors needing to delegate tasks to colleagues: 'When delegating care you must be satisfied that the person to whom you delegate has the knowledge, skills and experience to provide the relevant care or treatment; or that the person will be adequately supervised'. ${ }^{2}$ Typically, non-medical clinicians are provided with a weekly team meeting in which to discuss patients with psychiatrists as well as regular individual supervision. It has been assumed that this is providing appropriate support and supervision. However, there is limited evidence pertaining to the skills and confidence that non-medical staff have in assessing newly referred patients. A report by the Royal College of Nursing has highlighted a need for continuing postgraduate education to ensure high standards of community psychiatric nursing, including updating skills as an individual's role within a team changes. ${ }^{3}$ Similarly, the recent Francis inquiry emphasised the importance of ensuring individuals' skills are appropriately matched to their duties to ensure global high-quality care within the National Health Service (NHS). ${ }^{4}$ Being asked to perform skills beyond a clinician's training can be stressful and reduce performance as well as leading to burn-out. ${ }^{5}$

We hypothesised that as non-medical clinicians have been asked to undertake new patient assessments, a skills gap has emerged. We designed a service evaluation to test this hypothesis. The aims were to identify which professionals are undertaking new assessments, investigate the quality of these assessments and explore the level of confidence individuals have in carrying out this work. The primary method of investigation was a complete audit cycle, complemented by a cross-sectional survey.

\section{Method}

This was a service evaluation undertaken in the three community mental health teams (CMHTs) of the South Locality Older Adults Service (Oxford Health NHS Foundation Trust). South Oxfordshire has a population of approximately 134300 , including 33200 people over 60 years of age. ${ }^{6}$ The service evaluation was made up of three components occurring between June 2012 and July 2013 (Fig. 1). All of the components of the service evaluation were carried out in the same group of clinicians.

\section{Audit cycle}

The aim was to determine if existing practice meets agreed standards as to what information should be recorded during a routine new patient assessment. The initial audit covered the period 1 June to 31 July 2012, re-audited for 1 June to 31 July 2013. All consecutive new referrals were included. No international or nationally agreed guidelines as to how a new patient should be assessed could be located in either 2012 or 2013, so the proxy standard used within Oxford Health NHS Foundation Trust was chosen. This includes

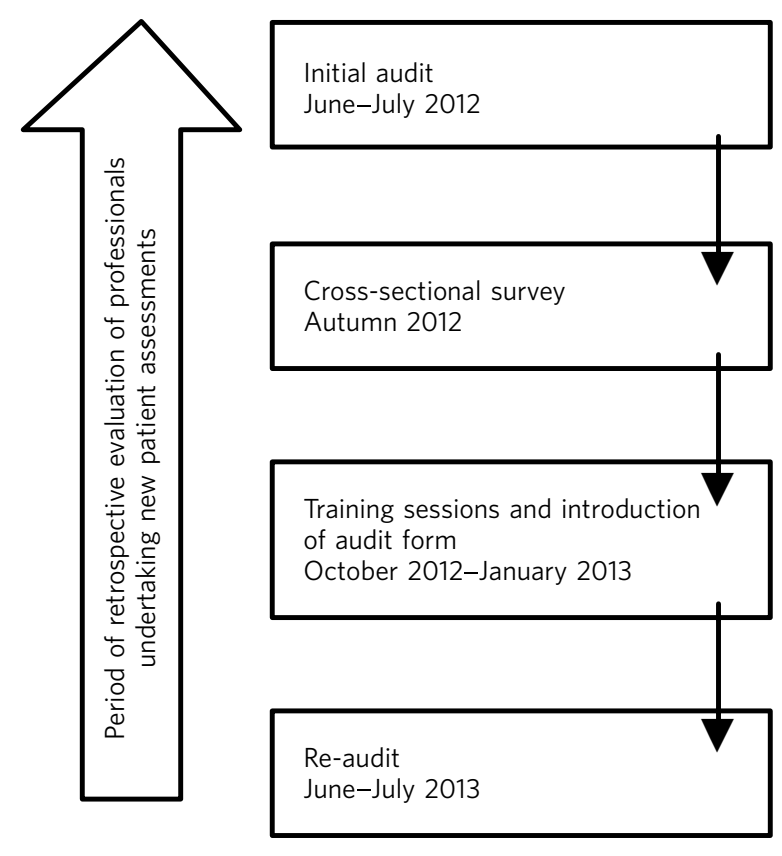

Fig 1 Timeline of events

the completion of each section of the 'core assessment' and 'risk assessment' of our $\mathrm{RiO}$ electronic notes system (www.servelec-group.com/Healthcare/RiO.html). Medical records were reviewed (by R.M.) first in November 2012 and then in August/September 2013: an audit tool form was completed for each individual. For each part of the assessment, if any comment was present pertaining to that area it was marked 'yes'. This included explanations as to why information was not available at that time. During October 2012-January 2013, a pilot set of 2-h training seminars and interactive workshops covering common psychiatric presentations were delivered weekly to multidisciplinary team clinicians. A new patient assessment form was introduced at the same time (available as online supplement DS1).

\section{Cross-sectional survey of non-medical clinicians' training needs}

We devised a 21-item questionnaire (online supplement DS2) covering confidence surrounding current assessment and education, plus unmet training need. This was distributed by email to 50 non-medical staff in 3 olderadult CMHTs. These included nursing staff, occupational therapists, social workers, mental health practitioners and psychologists. Healthcare assistants and support workers were excluded as they do not undertake new patient assessments. Participants returned an anonymous hard copy to their team manager.

\section{Retrospective evaluation of professionals undertaking new patient assessments}

All patient contacts (new and follow-ups) covering the period 1 March 2012 to 30 April 2013 were downloaded 
from the RiO electronic notes system. The profession of the assessing clinician was recorded as 'medical' (consultants and junior doctors) or 'non-medical' and proportions in each category calculated.

Upon the completion of the audit cycle and survey, and using feedback from the pilot training sessions, a programme of training in assessment skills was devised. This will be delivered by psychiatrists over 7 weeks on a yearly basis to all CMHT clinicians. Staff turnover and sickness will be closely monitored.

\section{Statistical analysis}

All results were entered into a Microsoft Excel spreadsheet for basic analysis. Audit data were analysed with SPSS v. 21 for Windows using unpaired chi-squared tests with $\alpha=0.05$.

\section{Results}

\section{Audit cycle}

In the initial audit, 40 consecutive referrals were received; this increased to 62 in 2013. The demographic profile of the sample remained unchanged for both audit cycles (Table 1). The professionals conducting assessments were community psychiatric nurses (CPNs; 64\%), psychiatrists (20\%) and occupational therapists (16\%). Of the psychiatrists, there were three consultants and three psychiatric trainees.

In 2012, the proportion of assessments clearly marked 'new assessment' and properly structured with subheadings was $45 \%$; this increased to $75 \%$ in 2013 after
Table 1 Results from audit cycle: sample characteristics

\begin{tabular}{lll} 
& 2012 & 2013 \\
\hline Gender, male (\%) & 44.0 & 42.5 \\
\hline Age, mean (years) & 79.5 & 80.0 \\
\hline Referral from primary care (\%) & 93.0 & 95.0 \\
\hline $\begin{array}{l}\text { Time from assessment to } \\
\text { documentation complete (days) }\end{array}$ & 4.4 & 3.8 \\
\hline
\end{tabular}

the introduction of an assessment form $(P=0.003)$. In 2012, the information most frequently omitted from assessment was medication history, family history, use of substances and risk assessment (Table 2). With nonpsychiatrist clinicians, there was a tendency to list all living family members under family history rather than record the presence or absence of mental disorder. However, this was not the case in assessments done by psychiatrists (e.g. 2013: 83\% v. 0\%). By 2013 there had been a significant improvement in recording of psychiatric history, medications, substance use, mental state examination and risks (Fig. 2). However, out of $17 \mathrm{RiO}$ subsections, only 7 had been completed in at least $75 \%$ of assessments. Psychiatrists were significantly more likely to record at least $90 \%$ of $\mathrm{RiO}$ sections than non-medical staff ( $81 \%$ v. $10 \%$ respectively; $P<0.001)$.

Evaluation of cognition is an important part of assessment in older adults. In 2012, $70 \%$ of assessments included information on cognition and bedside cognitive

\begin{tabular}{|lll|}
\hline Table 2 Results from audit cycle: assessments & \multicolumn{2}{c|}{$\begin{array}{l}\text { Assessments containing any information relating } \\
\text { to the subject, \% }\end{array}$} \\
\cline { 2 - 3 } Subsection of RiO core assessment & 2012 & 2013 \\
\hline Reason for referral & 82.5 & 90.9 \\
\hline Comment on who was present at the interview & 80 & 82 \\
\hline History of presenting complaint & 90 & 89.3 \\
\hline Past medical history & 52.5 & 59 \\
\hline Past psychiatric history & 52.5 & 0.0213 \\
\hline Medications & 40 & 72.7 \\
\hline Family history & 42.5 & 76 \\
\hline Personal history & 50 & 44 \\
\hline Social history & 92.5 & 48.5 \\
\hline Alcohol & 22.5 & 85 \\
\hline Smoking & 17.5 & 45.5 \\
\hline Substance use & 15 & 45.5 \\
\hline Forensic history & 20 & 45.5 \\
\hline Pre-morbid personality & 35 & 28.7 \\
\hline Collateral history & 80 & 28.7 \\
\hline Mental state examination & 50 & 71.2 \\
\hline Risk assessment & 35 & 66.7 \\
\hline Diagnostic impression & 80 & 66.7 \\
\hline Management planning & 95 & 0.002 \\
\hline
\end{tabular}

a. Chi-squared test. Non-significant $P$ values not given. 


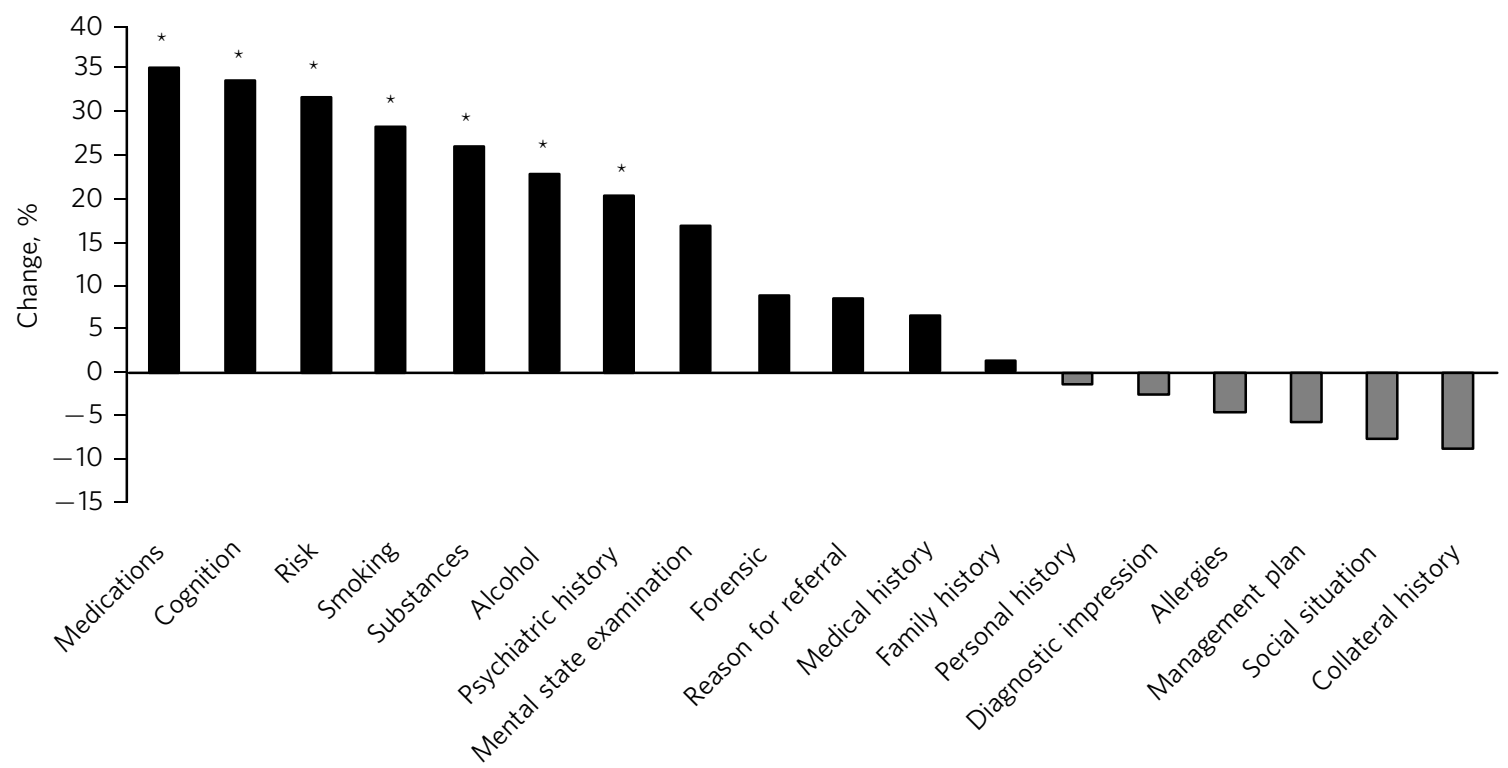

Fig 2 Change in contents of new patient assessments $2012-2013 .{ }^{\star} P<0.05$.

tests; this fell to $58 \%$ in $2013(P=0.04)$. However, for patients referred with cognitive impairment, more than 95\% had evidence of cognitive testing in both years.

\section{Cross-sectional survey of assessment confidence and unmet training needs}

This survey took place between the two audits but before the pilot intervention (Table 3). Overall, 36 questionnaires were returned (72\%), representing CPNs (50\%), social workers (17\%) and occupational therapists (17\%). Three-quarters $(75 \%)$ of respondents felt at least 'partially confident' to assess a new patient, with $22 \%$ reporting 'no confidence'. Similarly, $75 \%$ reported feeling 'stressed or unsupported' while doing the assessment. Less than half of staff (44\%) reported familiarity with the ICD-10 criteria for mental health disorders, ${ }^{8}$ and only $25 \%$ felt confident to use them to aid diagnosis. The majority of staff (80\%) felt confident to 'cluster' patients according to type and severity of illness.

In all, 86\% were keen for training in assessment, diagnosis and management of mental disorder. The conditions for which training was most frequently requested were (in order) bipolar disorder, depression, anxiety disorders, schizophrenia, personality disorders and dementia. The most popular methods of delivering training were seminars (83\%) and 1-day short courses (78\%). Most staff $(85 \%)$ felt it was essential to have accreditation recognised by employers for attending training.

\section{Retrospective evaluation of professionals undertaking new patient assessments}

Between March 2012 and April 2013, 485 new patient assessments were carried out within South Locality CMHT. In total, 41 individual clinicians were involved in the assessments, with $84 \%$ of assessments being conducted by one person. The breakdown of professionals involved was as follows: $60 \%$ CPNs, $20 \%$ psychiatrists, $16 \%$ occupational therapists, $4 \%$ social workers. The majority of new patient assessments were carried out by non-medical clinicians: $72.4 \%$ v. $27.6 \%$. Similarly, $86.2 \%$ of follow-up contacts were carried out by non-medical staff. Of the new assessments by medical staff, $58 \%$ were done by consultants.

\section{Staff turnover and sickness}

During the period from June 2012 to June 2013 the turnover of non-medical clinicians within the CMHT was $50 \%$ (compared with $12 \%$ trust wide). ${ }^{8}$ The average within the trust at that time was $8 \%$. At the time of the initial audit, $12 \%$ of staff were on long-term sick leave, including two band 7 nurses (1.8\% trust wide).

\section{Discussion}

This service evaluation investigated which professionals are undertaking new patient assessments and investigated unmet training needs of the clinicians involved. We hypothesised that a skills gap has emerged as more non-medical clinicians have started to participate in assessments and that they find these new duties very stressful; our results corresponded with this hypothesis.

The Royal College of Psychiatrists recommends that CMHTs should 'ensure the appropriate numbers of professionals with appropriate skills and competencies are in place to respond to local needs . . . for assessment'. ${ }^{9}$ Our surveys and audit clearly show that the majority of new patient assessments are now being done by non-medical clinicians and that they frequently do not feel confident to undertake this role. Not only does this pose clinical risks, but also contributes to rising financial costs due to high rates of stress-related sickness and rapid staff turnover. Our local experience is that many staff on long-term sick leave are experiencing 'stress, anxiety or depression'; this tallies with national data. ${ }^{5,8}$ The way that mental health services commissioning is now linked to diagnostic clustering means 


\begin{tabular}{lc} 
Table 3 & $\begin{array}{l}\text { Cross-sectional survey results }(n=36 \\
\text { respondents in total) }\end{array}$ \\
$\begin{array}{lc}n=36 & \text { Respondents } \\
\%\end{array}$ \\
\hline Profession of assessing clinician \\
CPN & 50 \\
Social worker & 17 \\
Occupational therapist & 17 \\
Psychologist & 9 \\
Support worker/other & 8 \\
\hline Level of confidence in assessing a new patient & 25 \\
Confident & 50 \\
Less confidence & 22 \\
No confidence & 2.8 \\
No comment & \\
\hline Familiarity with ICD-10 criteria & 44 \\
Yes & 39 \\
Partly & 17 \\
No & 25 \\
\hline Confidence in using ICD-10 criteria to make a diagnosis & 33 \\
Confident & 28 \\
Less confidence & 11 \\
No confidence & \\
No comment & \\
\hline
\end{tabular}

How often you feel stressed, unsupported when

assessing a newly referred patient?

Most of the time 64

Sometimes $\quad 11$

Not at all $\quad 22$

Would you like an opportunity to undertake

training in the following? (yes/no) ${ }^{a}$

Information on mental disorders 75

Assessment and diagnosis of mental disorders $\quad 86$

Updates from recent research $\quad 94$

Six disorders clinicians would most like training

on (in preference order)

Bipolar disorder

Depression

Anxiety disorders

Schizophrenia

Personality disorder

Dementia

22

Preferred method of teaching (in order)

Short courses (1-2 days)

$\begin{array}{ll}\text { E-learning resources } & 47\end{array}$

Formal academic course and qualification 39

How important is it to you to gain an

accreditation that is recognised by your

employers and other organisations for the

training that you undertake?

Very important

Quite important

Not important

No comment made

94

What would be the most important reason to

you to undertake further training?

To improve my clinical practice

For personal development

To enhance my CV

To increase the likelihood of promotion Other reason

CPN, community psychiatric nurse.

a. Only 'Yes' responses given.

that poor knowledge of diagnostic categories and grading of severity of mental health disorders could have financial implications. These implications could be reduced by providing appropriate training. Adequate knowledge of the local area and its resources is also important and this is hard to achieve with high staff turnover.

Our initial audit highlighted the poor quality of risk assessments undertaken during new patient assessments. Recent publications have alerted us to the need for high-quality risk assessment in older adults, especially for suicide and self-harm. ${ }^{10}$ This was an area of great concern in the 2012 audit, but the 2013 re-audit demonstrated that very simple measures - an assessment form and some pilot teaching sessions - made a significant improvement in our teams' skills and documentation. Similarly, Huh et $a l^{11}$ report that a 1-day course in suicide risk assessment for healthcare professionals working with older adults was highly effective at increasing staff confidence and the quality of risk assessment. The Department of Health has previously emphasised the need to provide a range of flexible approaches to education and training, ${ }^{12}$ and this is especially important as we increasingly recognise different styles of learning and diversify our working patterns. Key to this will be standardising access to training, for example making sure that all professionals have similar amounts of study leave provision.

We demonstrated that the majority of staff would like to undertake further training in the form of seminars or short courses, and would like accreditation for this. We have been unable to find any similar audit or research data with which to compare our results, but the Royal College of Nursing reports similar findings. ${ }^{3}$ Their survey of over 800 UK mental health nurses found that $89 \%$ would like further training in 'acute mental health conditions' and the favoured delivery methods were also teaching sessions or short courses. This work only included nurses, whereas our study includes all non-medical clinicians, but the demographics are otherwise similar. It could be argued that the 'team' nature of CMHTs (e.g. having staff supervision and a multidisciplinary team meeting at which new cases are presented to the consultant) allows for appropriate clinical guidance, but we have found it can be difficult to provide such guidance when faced with a lack of information gathered at an initial assessment.

\section{Limitations}

The main limitation of this service evaluation is the sample size and the fact that it covers only one geographic area. It might also be hard to generalise to outside older adult psychiatry. The response rate for the questionnaire was low, which may be partially explained by the work having occurred during the holiday season, but other ways of reaching staff need to be investigated. It should also be remembered that staff have highly variable experience in terms of the years of practice; we cannot expect newly qualified colleagues to be comparable to those with more years of service and we did not collect this information.

\section{Assessment training}

We propose to improve standards in new patient assessment and increase clinicians' skills and confidence in our area by 
providing a comprehensive training programme within normal working hours for all non-medical clinicians and junior doctors in the CMHT. This will be delivered as seven 2-3-h interactive seminars and will cover general assessment, risk assessment and management of common disorders presenting to old age psychiatry (see online supplement DS3). It will be provided at least yearly to include all incoming staff and, while led by consultants, will provide a platform for psychiatric trainees to enhance their teaching skills. Re-audits of new patient assessment structure and content will occur yearly.

Assessment is the foundation of high-quality management in psychiatry: we should work hard to ensure that all clinicians are appropriately skilled and supported to manage the vulnerable patients presenting to our services. ${ }^{13}$ Psychiatrists should take a leading role in delivering appropriate knowledge whereas mental health trusts should facilitate training and seek ways to encourage and reward aspiration.

\section{Acknowledgements}

We thank all staff of the South Locality team for assisting with data collection and providing support with the project. Special thanks go to Marion Evans who downloaded the RiO data to establish who had undertaken assessments between 2012 and 2013

\section{About the authors}

Dr Svetlana Hemsley and Dr Aneeba Anwar are specialist trainees in old age psychiatry, Dr Rebecca McKnight is an academic clinical fellow in psychiatry, Sarah Jones is a service manager and Dr Lola Martos is a consultant psychiatrist, all working at the South Locality Older Adults Community Mental Health Team, Abingdon Mental Health Centre, Oxford Health NHS Foundation Trust, Abingdon, UK.

\section{References}

1 Gournay K. The changing face of psychiatric nursing: Revisiting . . . Mental health nursing. Adv Psychiatr Treat 2005; 11: 6-11.

2 General Medical Council. Good Medical Practice. GMC, 2013.

3 Jones J. What Education and Training do Mental Health Nurses Want? A Survey of Qualified Mental Health Nurses Working in Acute Inpatient Psychiatric Settings in the UK. Royal College of Nursing, 2001.

4 Francis R. Report of the Mid Staffordshire NHS Foundation Trust Public Enquiry. TSO (The Stationery Office), 2013.

5 Mark G, Smith AP. Occupational stress, job characteristics, coping, and the mental health of nurses. Br J Health Psychol 2012; 17: 505-21.

6 Oxfordshire County Council. 2011 Census Population Data: South Oxfordshire. Office for National Statistics, 2011. Available at: http:// insight.oxfordshire.gov.uk/cms/population (accessed September 2014).

7 World Health Organization. The ICD-10 Classification of Mental and Behavioural Disorders. WHO, 1992.

8 Halford J. Oxford Health NHS Foundation Trust: Workforce Performance 2013. Oxford Health NHS Foundation Trust, 2013.

9 Welsh Assembly Government. The Role of Community Mental Health Teams In Delivering Community Mental Health Services: Interim Policy Implementation Guidance and Standards. Welsh Assembly Government, 2010.

10 Dennis MS, Owens DW. Self-harm in older people: a clear need for specialist assessment and care. Br J Psychiatry 2012; 200: 356-8.

11 Huh JT Weaver CM, Martin JL, Caskey NH, O'Riley A, Kramer BJ. Effects of a late-life suicide risk-assessment training on multidisciplinary healthcare providers. J Am Geriatr Soc 2012; 60: 775-80.

12 Department of Health. Making a Difference: Strengthening the Nursing, Midwifery and Health Visiting Contribution to Health and Healthcare. Department of Health, 2001.

13 National Health Service. The NHS Constitution: THE NHS Belongs To Us All. National Health Service, 2013.

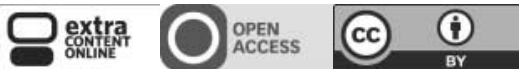

